in a patient with idiopathic pulmonary arterial hypertension. J Heart Lung Transplant 2008; 27: 466-468.

19 Olsson KM, Simon A, Strueber M, et al. ; Extracorporeal membrane oxygenation in nonintubated patients as bridge to lung transplantation. Am J Transplant 2010; 10: 2173-2178.

20 Wiklund L, Haraldsson A, Selimovic N, et al. Extracorporeal membrane oxygenation as a bridge to lung transplantation in a patient with persistent severe porto-pulmonary arterial hypertension following liver transplantation. Eur J Cardiothorac Surg 2011; 39: 777-778.

21 Hämmäinen $\mathrm{P}$, Schersten $\mathrm{H}$, Lemström $\mathrm{K}$, et al. Usefulness of extracorporeal membrane oxygenation as a bridge to lung transplantation: a descriptive study. J Heart Lung Transplant 2011; 30: 103-107.

22 Strueber M. Extracorporeal support as a bridge to lung transplantation. Curr Opin Crit Care 2010; 16: 69-71.

23 Walles T. Clinical experience with the iLA Membrane Ventilator pumpless extracorporeal lung-assist device. Expert Rev Med Devices 2007; 4: 297-305.
24 de Perrot M, Granton JT, McRae K, et al. Impact of extracorporeal life support on outcome in patients with idiopathic pulmonary arterial hypertension awaiting lung transplantation. J Heart Lung Transplant 2011; 30: 997-1002.

25 Strueber M, Hoeper MM, Fischer S, et al. Bridge to thoracic organ transplantation in patients with pulmonary arterial hypertension using a pumpless lung assist device. Am J Transplant 2009; 9: 853-857.

26 Fischer S, Hoeper MM, Tomaszek S, et al. Bridge to lung transplantation with the extracorporeal membrane ventilator Novalung in the veno-venous mode: the initial Hannover experience. ASAIO J 2007; 53: 168-170.

27 Fischer S, Simon AR, Welte T, et al. Bridge to lung transplantation with the novel pumpless interventional lung assist device NovaLung. J Thorac Cardiovasc Surg 2006; 131: 719-723.

28 Humbert M, Sitbon O, Chaouat A, et al. Survival in patients with idiopathic, familial, and anorexigen-associated pulmonary arterial hypertension in the modern management era. Circulation 2010; 122: $156-163$.

DOI: 10.1183/09059180.00005511

\title{
Drug-induced eosinophilic pleural effusion
}

\section{To the Editors:}

We read with great interest the article by ALAGHA et al. [1] in the June issue of the European Respiratory Review. Since, in our opinion, eosinophilic pleural effusion (EPE), and drug-induced EPE in particular, is an interesting issue, we would like to add some comments to this article.

It should be realised that our knowledge on drug-induced EPE comes almost exclusively from case reports. Although none of the larger series presenting the aetiology of EPE reported the true incidence of drug-induced EPE, the percentage of patients with drug-induced EPE seems to be low. Nevertheless, as in the majority of these patients drug discontinuation is sufficient for resolution of pleural effusion, pharmacological agents should always be considered as a potential cause of pleural effusion, particularly in EPE.

Although numerous drugs can induce pleuritis and pleural effusion, the list of agents associated with eosinophilic pleuritis is not extensive [2-4]. Some drugs used in psychiatry and neurology are some of the most important, including valproic acid (and its derivatives) and dantrolene [5-8]. EPE was also reported as a complication of treatment with tazinidine, trimipramine and fluoxetine [9-11]. It is interesting that, in a substantial number of reports on drug-induced EPE, two or more drugs that can potentially induce pleural effusion were used. This was the case in the first patient described by ALAGHA et al. [1], who was treated with dantrolene and fluoxetine. Similarly, two patients with EPE related to valproic acid and sodium valproate, respectively, were also treated with clozapine $[12,13]$. Interestingly, when valproic acid and clozapine are used together, clozapine might be a true cause of pleural effusion as demonstrated by DALY et al. [14]. Clozapine-induced pleuritis was reported in one patient who was concomitantly treated with olanzapine [15]. These examples show the crucial role of thorough clinical evaluation, including drug withdrawal and re-challenge in making a causative diagnosis of druginduced pleural effusion.

In order to list the most important drugs associated with EPE, two other groups should also be presented. The first is quite inhomogeneous and includes drugs mainly used in cardiology and internal medicine, these are: warfarin, diltiazem, simvastatin, imidapril, propylthiouracyl and mesalamine. The second group includes the following chemotherapeutics and antibiotics: nitrofurantoin, daptomycin and tosufloxacin. A comprehensive review on drug-induced pleural effusion was published in 2004 [16].

There is one general statement regarding EPE in the report by ALAGHA et al. [1] which, in our opinion, requires correction and comment. Citing an article by ADELMAN et al. [17], the authors state that a specific cause of EPE could be identified in only $25 \%$ of patients [1]. We would like to emphasise that, although the paper by ADELMAN et al. [17] has long been one of the most important sources of our knowledge on epidemiology of EPE, it was based on analysis of 23 papers published between 1955 and 1982. Thus, the data from that study are quite old. However, even in this paper the cause of EPE could be identified in $65 \%$ of patients and only $35 \%$ of cases were classified as "idiopathic" EPE [17]. Recently, some relevant articles on EPE epidemiology have been published. Our analysis of the largest, single-centre treated group of patients with EPE showed that a causative diagnosis was not established in only $14.1 \%$ of these patients [18]. A similar result (15.6\% idiopathic EPEs) was reported by MARTINEZ-GARCIA et al. [19]. It should also be noted that other authors reported a higher percentage of patients with EPE of unknown origin. This percentage, however, did not exceed 30$32 \%[2,20]$. A lower number of patients with unknown cause of $\mathrm{EPE}$ in the recent studies might be related to the advances in the diagnosis of pleural effusion, but also to changing aetiology of EPE. This was elegantly demonstrated in a paper recently 
published by ОвА and ABU-SALAH [21]. While malignancies were responsible for only $8 \%$ of all EPEs reported by ADELMAN et al. [17], they accounted for 111 (30\%) out of 369 EPE cases reported in the six studies published in the past decade [21]. Cumulative prevalence of malignancies in patients with EPE reported in 17 studies published between 1967 and 2009 has increased from 7\% to $25 \%$ [21]. In our large series, malignancies were the most common cause of EPE, responsible for 35\% of EPE cases [18].

Some clinical and laboratory data might help to roughly predict the probability of various aetiologies of EPE. Analysis of different studies shows that the epidemiology of EPE might be closely related to the local epidemiological setting. The percentage of tuberculous effusion in EPEs developing in populations with a high prevalence of tuberculosis was as high as $10-39.6 \%[20,22]$, while it was only $0-2 \%$ in the setting of low or intermediate tuberculosis prevalence $[2,18,23]$. In our previous study, an interesting relationship was found between the percentage of eosinophils and EPE aetiology. The percentage of patients with malignant EPE was inversely related to the percentage of eosinophils in pleural effusion. An opposite relationship was found for patients with pleural effusion of unknown origin [18]. A similar relationship between the probability of malignancy and eosinophil percentage was also demonstrated in a recent meta-analysis [21]. The two cases reported by AlAGHA et al. [1] seem to be consistent with the relationship presented above. The percentage of pleural fluid eosinophils was high (55 and 75\%, respectively) and both described patients had a non-malignant aetiology of EPE [1].

To summarise, we believe drug reactions should be considered as a potential cause of pleural fluid accumulation in all patients with EPE. However, drug-induced EPE should be considered on a broad basis of EPE aetiology. Since a specific cause of EPE can be identified in the majority of cases, all patients with this type of pleural effusion require rigorous and full diagnostic algorithm.

\section{R. Krenke* and R.W. Light ${ }^{\#}$}

*Dept of Internal Medicine, Pneumonology and Allergology, Medical University of Warsaw, Warsaw, Poland. "Division of Allergy, Critical Care Medicine and Pulmonary Diseases, Vanderbilt University, Nashville, TN, USA.

Correspondence: R. Krenke, Dept of Internal Medicine, Pneumonology and Allergology, Medical University of Warsaw, Banacha 1A, 02-097 Warsaw, Poland. E-mail: rafalkrenke@interia.pl

Statement of Interest: R. Krenke's travel to the 2008 and 2009 American Thoracic Society conference was funded by Boehringer Ingelheim.

Provenance: Submitted article, peer reviewed.

\section{REFERENCES}

1 Alagha K, Tummino C, Sofalvi $\mathrm{T}$, et al. Iatrogenic eosinophilic pleural effusion. Eur Respir Rev 2011; 20: 118-120.
2 Kalomenidis I, Light RW. Eosinophilic pleural effusions. Curr Opin Pulm Med 2003; 9: 254-260.

3 Light RW, ed. Pleural Diseases. 5th Edn. Philadelphia, WoultersKluwer/Lippincott Williams and Wilkins, 2007.

4 Morelock SY, Sahn SA. Drugs and the pleura. Chest 1999; 116: 212-221.

5 Bullington W, Sahn SA, Judson MA. Valproic acid-induced eosinophilic pleural effusion: a case report and review of the literature. Am J Med Sci 2007; 333: 290-292.

6 Joshi P, Kasmani R, Hollingsworth J, et al. Divalproex sodiuminduced eosinophilic pleural effusion. Am J Ther 2009; 16: 593-595.

7 Urano T, Nishiumi M, Tajiri S, et al. Eosinophilic pleurisy induced by dantrolene. Tokai J Exp Clin Med 2005; 30: 189-192.

8 Lê-Quang B, Calmels P, Valayer-Chaléat E, et al. Dantrolene and pleural effusion: case report and review of literature. Spinal Cord 2004; 42: 317-320.

9 Moufarrege G, Frank E, Carstens DD. Eosinophilic exudative pleural effusion after initiation of tizanidine treatment: a case report. Pain Med 2003; 4: 85-90.

10 Hatzinger M, Stohler R, Holsboer-Trachsler E. Eosinophile pleuritic und Hepatopathie unter Trimipramin-Therapie [Eosinophilic pleuritis and hepatopathy under trimipramine therapy]. Schweiz Med Wochenschr 1991; 121: 910-912.

11 Behnia M, Dowdeswell I, Vakili S. Pleural fluid and serum eosinophilia: association with fluoxetine hydrochloride. South Med J 2000; 93: 611-613.

12 Fernández-Pérez R, Alvarez-Dobaño JM, Suárez-Antelo J, et al. Eosinophilic pleural effusion associated with the addition of sodium valproate. J Clin Psychopharmacol 2009; 29: 310-311.

13 Kravetz JD, Federman DG. Valproic acid-induced eosinophilic pleural effusion. South Med J 2003; 96: 803-806.

14 Daly JM, Goldberg RJ, Braman SS. Polyserositis associated with clozapine treatment. Am J Psychiatry 1992; 149: 1274-1275.

15 Boot E, de Haan L, Guzelcan Y, et al. Pericardial and bilateral pleural effusion associated with clozapine treatment. Eur Psychiatry 2004; 19: 65.

16 Huggins JT, Sahn SA. Drug-induced pleural disease. Clin Chest Med 2004; 25: 141-153.

17 Adelman M, Albelda SM, Gottlieb J, et al. Diagnostic utility of pleural fluid eosinophilia. Am J Med 1984; 77: 915-920.

18 Krenke R, Nasilowski J, Korczynski $\mathrm{P}$, et al. Incidence and aetiology of eosinophilic pleural effusion. Eur Respir J 2009; 34: 1111-1117.

19 Martinez-Garcia MA, Cases-Viedma E, Cordero-Rodriguez PJ, et al. Diagnostic utility of eosinophils in the pleural fluid. Eur Respir J 2000; 15: 166-169.

20 Ozkara SK, Turan G, Başyiğit I. Clinicopathologic significance of eosinophilic pleural effusions in a population with a high prevalence of tuberculosis and cancer. Acta Cytol 2007; 51: 773-781.

21 Oba $Y$, Abu-Salah T. The prevalence and diagnostic significance of eosinophilic pleural effusions: a meta-analysis and systematic review. Respiration 2011; [Epub ahead of print DOI: 10.1159/ 000327200].

22 Kamel A, Chabbou A, El Gharbi B. Apport diagnostique de l'eosinophilie pleurale [Eosinophilic pleural effusion]. Rev Pneumol Clin 1989; 45: 118-122.

23 Rubins JB, Rubins HB. Etiology and prognostic significance of eosinophilic pleural effusions. A prospective study. Chest 1996; 110: $1271-1274$ 